\title{
New York 5 to 9: Studying the City That Never Sleeps
}

\author{
Mehmet Dede \\ The Hartt School, University of Hartford \\ This paper was presented at the 2019 International Summit of the \\ Music \& Entertainment Industry Educators Association \\ March 21-23, 2019
}

\section{https://doi.org/10.25101/19.32}

\begin{abstract}
In 2018, the first study on the New York nighttime economy and creative spaces was published. Creative Footprint NYC presented data from active music venues, clubs, theaters and artist spaces that regularly program music events in New York. Fifteen data researchers and three data analysts, as well as 150 experts with close ties to the local scene evaluated nearly 500 venues. The paper explores some of the findings of the report and discusses the changing dynamics of New York music venues, advancing our understanding of their economic and creative output. The full report can be downloaded at www.creative-footprint.org.

Keywords: New York City nightlife, nighttime economy, creative spaces, art spaces, policy framework, urban policy strategies
\end{abstract}

\section{Introduction}

From the days of big bands playing hot jazz in Harlem in the early twentieth century, to sounds emanating from Tin Pan Alley and, later, the Brill Building, from folk cafes in Greenwich Village post-World War II, to punk music rolling down the Bowery in the $70 \mathrm{~s}$, then merging into head-bopping sounds blasting from speakers in the parks of the Bronx, there are many musical genres that can be identified with the Big Apple. Yet for all the iconic performers, musical styles, and venues, there has not been an objective study of the circumstances - creative, financial, regulatory, and otherwise - in which live music is created and shared with audiences today. Not since the arrival of hip-hop in the $80 \mathrm{~s}$, has there been a major music force that is associated with New York. Did we run out of music styles? Did music become so fragmented since Napster that it is unrealistic to expect another major genre to be born on the streets of New York? Where are the new Minton's Playhouses, the Village Gates, the CBGB's, the Paradise Garages, the spaces and people who supported nascent music styles? How do smaller venues in New York fare today?

After being involved in running a music venue in the East Village since 2010, the author of this paper can attest to the challenges of operating a small business in New York today. The paper may be looking at New York specifically, but the findings ring true for any city that wants to develop and protect its live music communities.

This paper is an overview of a seminal study, Creative Footprint NYC, conducted on New York's nighttime economy to measure its health and vitality. From mapping out venues based on size and locales, to regulations that effect their operations, researchers evaluated music venues with the help of local experts, including this author, by gathering over 25,000 data points and using fifteen venue-specific criteria. The report was envisioned by Berlin Club Commissioner Lutz Leichsenring and former Amsterdam Night Mayor Mirik Milan, two experienced music and nightlife advocates who have been involved in similar studies in other cities. Additional authors of this independent report include 
city planners, policy advisors, and university researchers.

\section{What is Creative Footprint NYC and Why is it Needed?}

Creative Footprint NYC is a cultural impact study that measures the well-being of the live music scene in New York. The recently established New York City Mayor's Office of Media and Entertainment reports that there are "more than 25,000 nightlife establishments Citywide (restaurants, bars, venues, etc.). In 2016 the nightlife industry supported 299,000 jobs with $\$ 13.1$ billion in employee compensation and $\$ 35.1$ billion in total economic output." ${ }^{1}$ A vibrant nightlife attracts talent, changemakers, and creative spaces, and, therefore, is a critical element in any city's economy.

\section{Creative Footprint NYC provides:}

1. A bird's eye view of the current state of New York City venues and their characteristics

2. A list of actions needed to create affordable creative spaces

3. A platform to start dialogue and to use venues as a catalyst for grassroots organization

\section{Definitions and Methodology}

Creative Footprint NYC defines a music venue as "any kind of indoor or outdoor venue with regular music programming, which is advertised publicly." A venue is expected to offer at least one event per month. Private events and parties including product launches and weddings do not count as music events.
The input and data for the report was gathered between November 2017 and June 2018 via online data mining and in-person focus groups. Regular meet-ups took place in different boroughs with local tastemakers who identified venues and graded them based on a set of predetermined criteria. The five boroughs of New York City are Manhattan, Brooklyn, Queens, The Bronx, and Staten Island.

A total of fifteen key data components were used for the methodology, which were grouped in three categories (Figure 1): 1) Space, 2) Content, and 3) Framework Conditions. Space covers the quantitative data (e.g., size, location, number of shows venue is hosting) found through online resources. Content includes the qualitative data (e.g., reputation of venue, how creative and experimental its programming is), and was generated with help from local experts like promoters, venue operators, DJs, performers, and producers. Finally, the Framework Conditions correspond to city laws, regulations, infrastructure, permits, and licenses.

\section{Qualitative Survey Results}

Since the late 1990s, two major music business trends left their mark in New York's live music space: First, the rollup of local promoters which gave birth to Live Nation and the corporate culture that came with the consolidation and second, the emergence of Brooklyn as a serious contender for mid-to-large-scale concerts across the East River from Manhattan. While commercial promoters were merging, the local scene also went through its own period of change serving a smaller but diverse audience — one that preferred underground and non-commercial sounds.

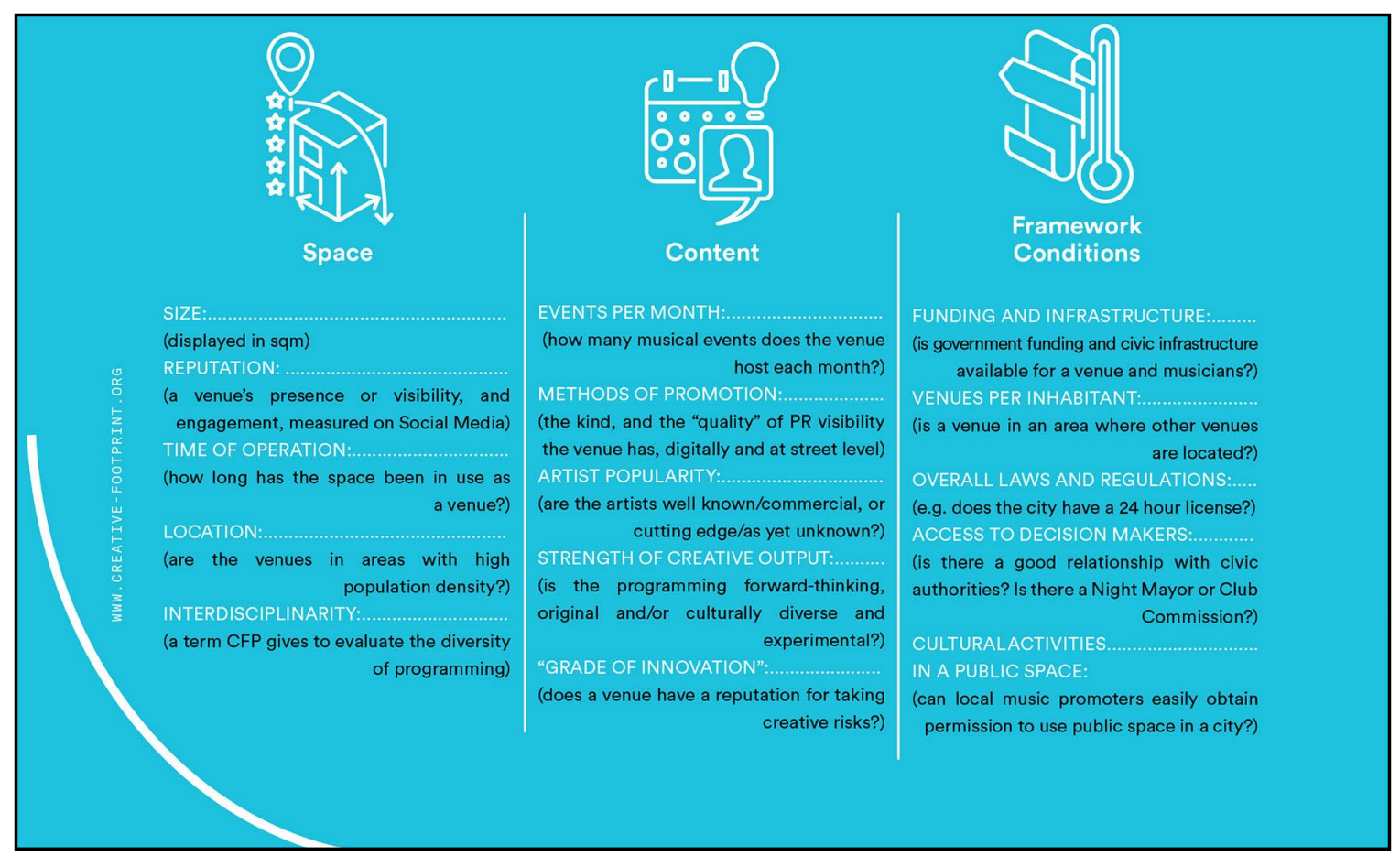

Figure 1. Data criteria (source: Creative Footprint NYC 2018). 
The results highlighted in this paper support these two trends. Given its status as one of the live music capitals of the world, it is not surprising to find that Manhattan has the highest number of music venues (260) with 53\% of total venues among all five boroughs of New York City. Brooklyn came in second (171 venues) with $35 \%$ of total venues. This is remarkable because most of these venues did not exist fifteen years ago and is the direct result of the live music renaissance that started in Brooklyn in the mid-2000s. Today, this trend continues as it expands further east to the border with Queens.

As seen in Figure 2, both Manhattan and Brooklyn lack small size venues for live music (those less than 900 square feet or 80 square meters, with a capacity of roughly 75 people or less). According to the "Music in New York City" report published in 2017 by the New York City Mayor's Office, $23 \%$ of small size music venues closed in the last fifteen years including iconic venues like CBGB and Wetlands. Considering that "it costs upwards of $\$ 1$ million to open a 100 to 300-person venue in New York City and as much as $\$ 5$ million to open a 500 to 1,000 -person venue due to construction costs, license complexity, regulatory scrutiny, and the resources required to pass inspections," ${ }^{2}$ new and small venues are not making up the difference yet.

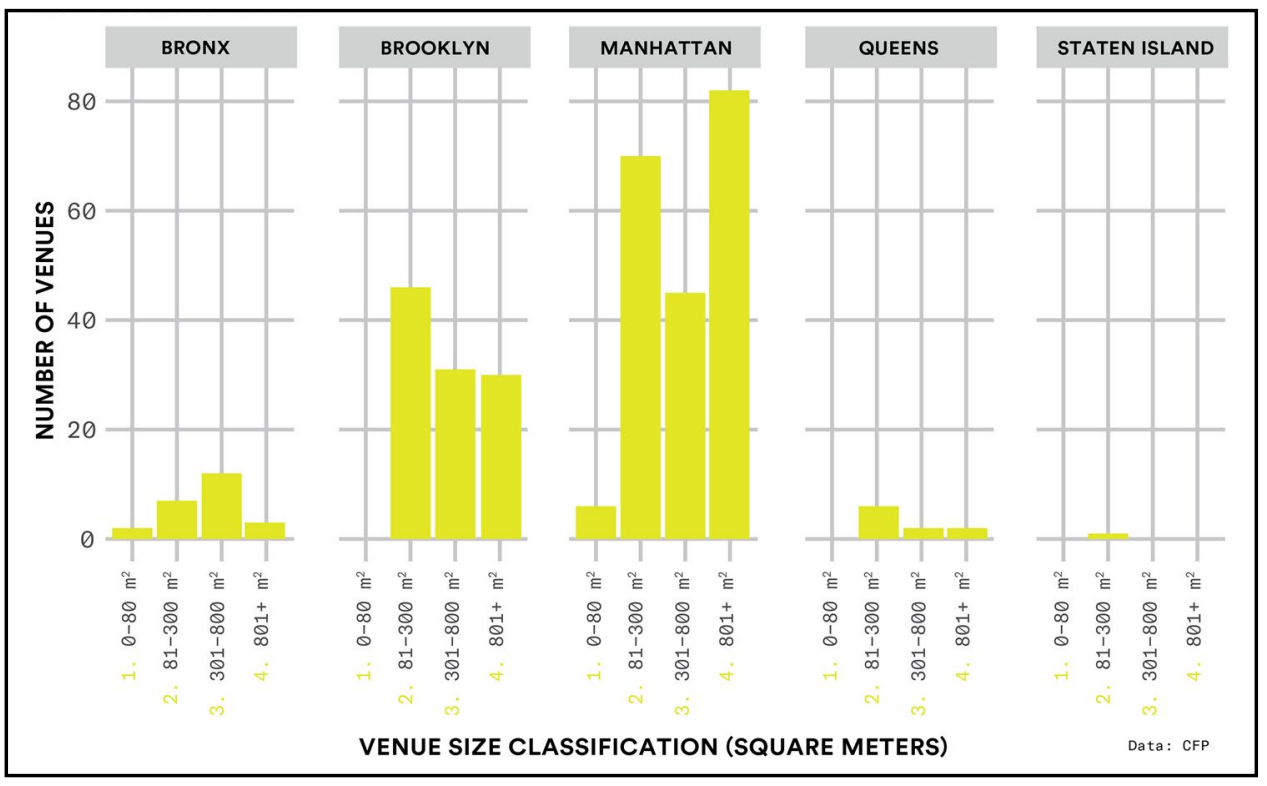

Figure 2. Venue size by borough (source: Creative Footprint NYC 2018).

The lack of small size venues aside, one would expect the number of venues to decrease, as venue sizes get bigger. With Brooklyn, this was precisely the case. However, in Manhattan the highest number of venues was in the large-size category (more than 80 venues that are 8,600 square feet or 801 square meters and up) - the reverse of the Brooklyn trend-proving that sizeable commercial venues have a large appeal once they establish their name.

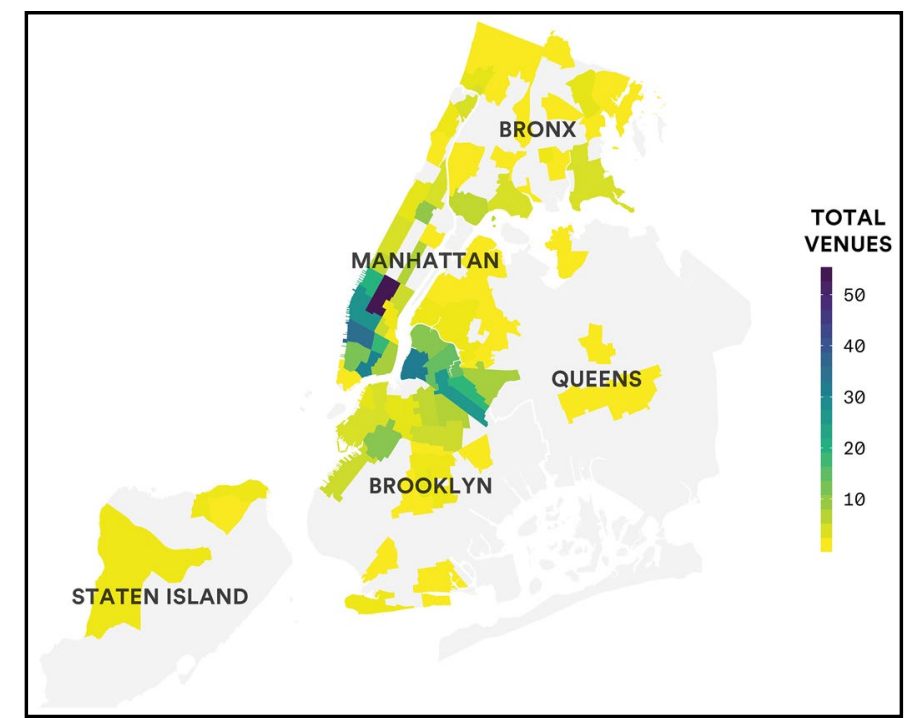

Figure 3. Venues by neighborhood (source: Creative Footprint NYC 2018).

Music venues in Manhattan are primarily clustered in Midtown and Lower Manhattan (East Village, Chinatown, Lower East Side). Midtown caters to touristy attractions with many venues and theaters twenty years or older. The East Village has historically been important for music and culture, and today benefits from a younger population with many colleges like New York University, Cooper Union, and School of Visual Arts in the vicinity. Like Brooklyn, the Lower East Side/Chinatown, too, experienced a renaissance in the last fifteen years and boasts a high number of venues today (31). ${ }^{3}$ In Brooklyn, the concentration is mainly on the Williamsburg-Bushwick corridor stretching east. The rest of the venues are scattered throughout the other boroughs (Figure 3).

The age of music venues (i.e., number of years in operation) in Figure 4 shows opposing results, between Manhattan and Brooklyn. While the oldest venues in Manhattan, those twenty or more years old, are in the majority (e.g., the Blue Note, The Apollo Theater, Bowery Ballroom), in Brooklyn it is the younger venues, most of them less than ten years old like Babies Alright, Rough Trade, and Brooklyn Steel that make up the majority. This can be traced back to the previously stated fact that Brooklyn has turned into a hot market for live music in the new millennium.

\section{Quantitative Survey Results}

The results reviewed so far are qualitative. How about the 


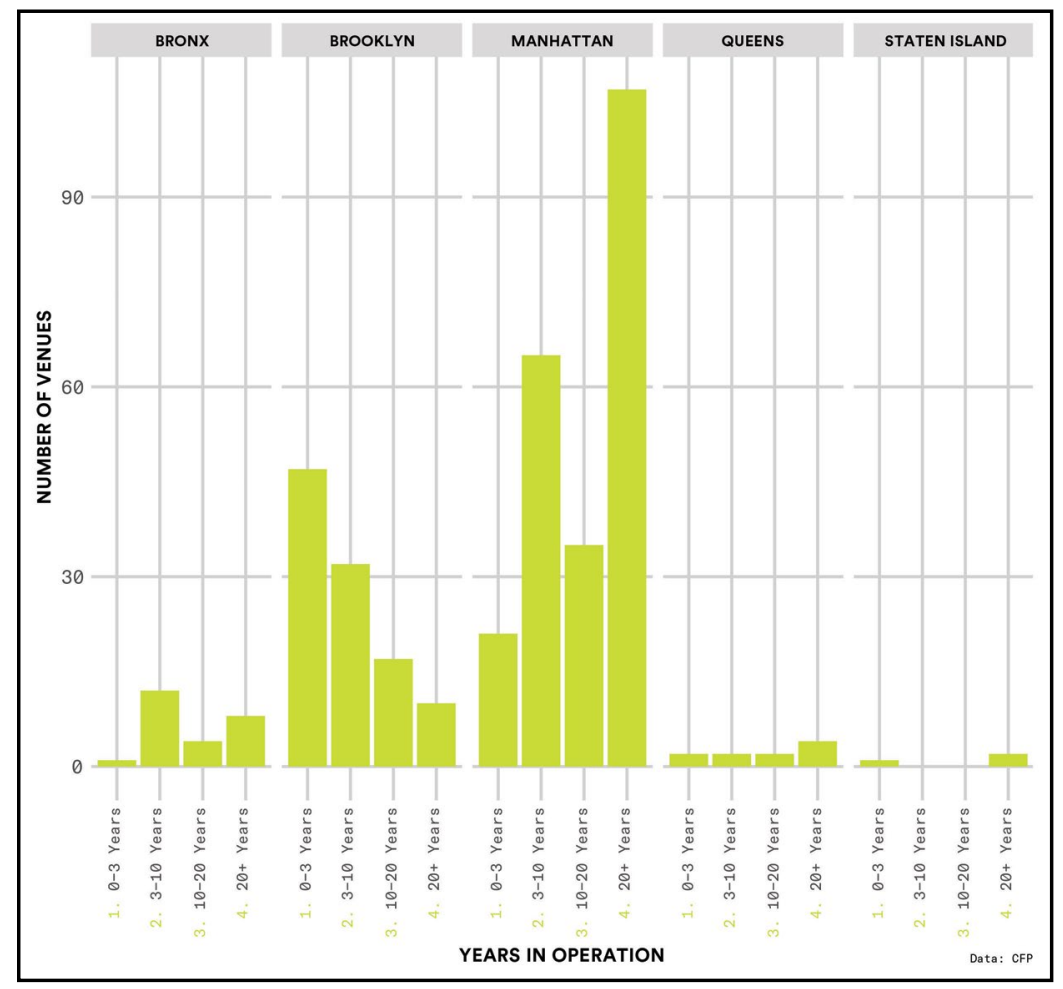

Figure 4. Venue age and boroughs (source: Creative Footprint NYC 2018). quantitative results? Take, for example, the question of how adventurous venues are with their programming. The Experimental Content Score measures whether an establishment is open to experimental trends, sounds, and art forms, as well as diverse performers and audiences including music from other parts of the world (Figure 5). The Manhattan-Brooklyn chasm plays out here again. Midtown Manhattan, a very commercial part of town, was also one of the most conservative in its programming, while Brooklyn was the most daring. It's also worth adding that venues in the Bronx are programming with increasing diversity.

The Creative Footprint NYC report processed more than 25,000 data points from nearly five hundred New York venues and presented them with fifteen key data sets in three distinct categories. These were covered earlier: Space (size, location, number of shows), Content (reputation of venue, how experimental the programming is), and Framework Conditions (city laws, regulations, permits, licenses). Based on survey results, New York scored an average of 7.29 out of 10.00 (Figure 6). According to the report, New York City did well with the Space

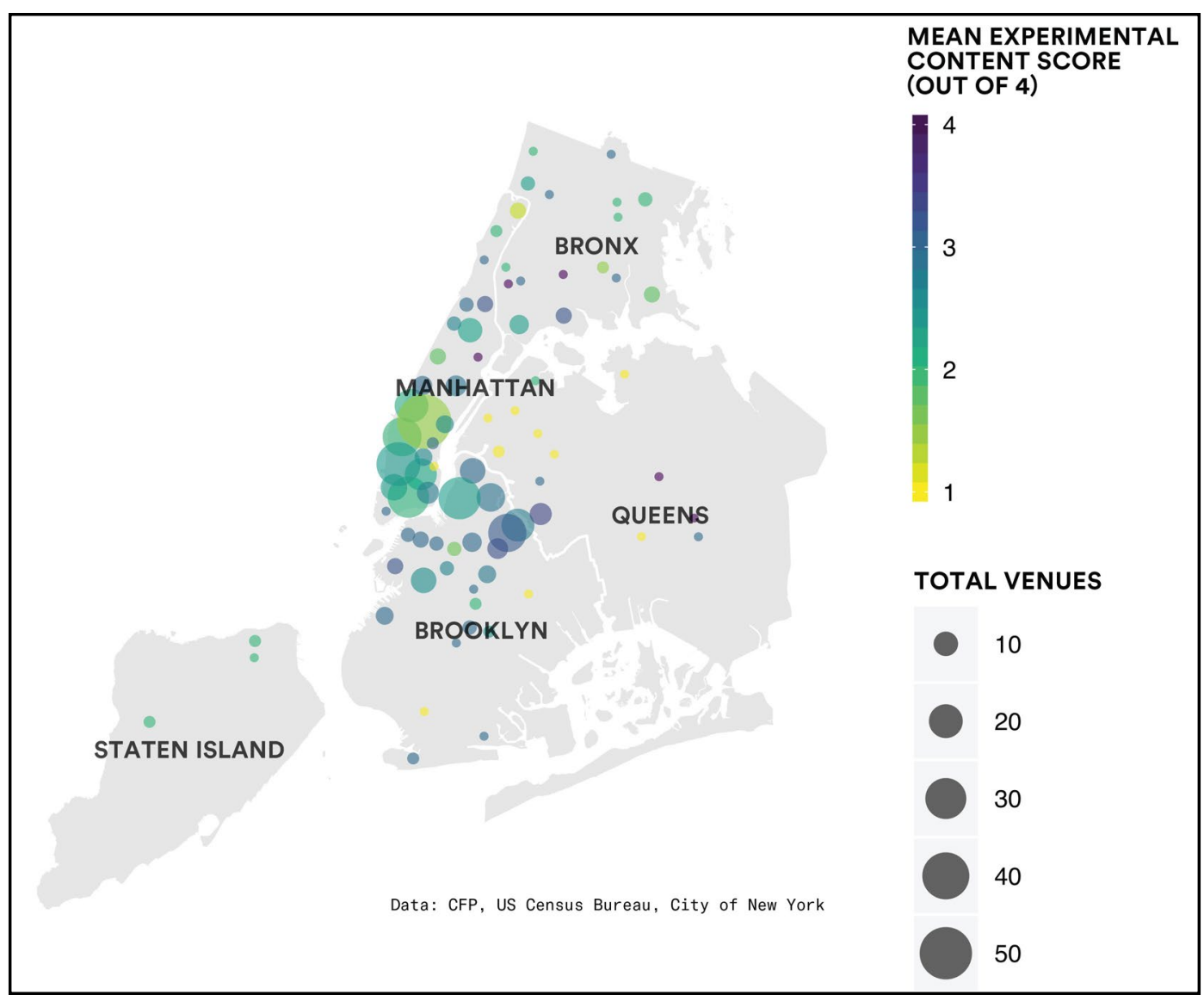

Figure 5. Mean Experimental Content score (source: Creative Footprint NYC 2018). 


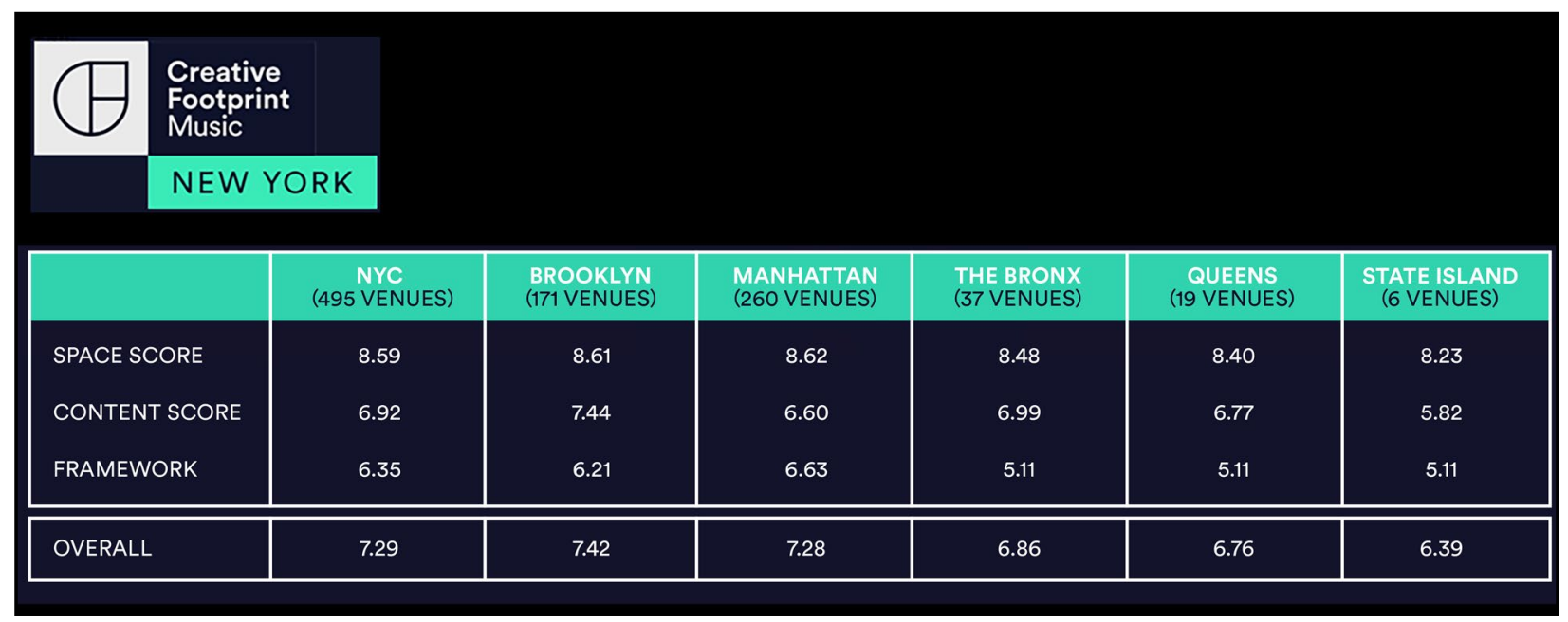

Figure 6. New York City scores (overall and by borough) (source: Creative Footprint NYC 2018).

category, but can improve its Content score/Diversity programming and Policy Framework.

\section{Principal Findings}

The report's four main findings can be summarized as follows:

- Venues younger than three years are the main drivers behind diversity programming, especially in Brooklyn (Figure 4). The lack of new and small-size venues is concerning since that's where experimentation starts without financial pressures. Consequently, the need to support new DIY venues with incentives, especially in their first few years of operation, is critical.

- Younger people tend to live in neighborhoods with more venues and accessible transportation (Figure $3)$.

- Rent prices generally correlate with the number of venues in an area. ${ }^{4}$ It is no secret that music venues and nightlife establishments add value to a neighborhood's appeal.

- Regulations and laws greatly affect the quality of nightlife. Outdated regulations must be revised to make way for modern, applicable regulations. A great example was the long-standing cabaret law, which was enacted in 1926 and prohibited dancing in venues and cabarets without a license. It was finally repealed in 2017.

\section{Key Takeaways}

In conclusion, continuous creativity is vital for the cultural health and economy of any city. DIY spaces and the creative people that run them occupy a critical place in the nighttime ecosystem and need support. Without affordable art spaces these venues cannot sustain themselves. Further, more legislation is needed to protect and nurture new venues. Appointing New York City's first Night Mayor is an important step the city took in recent years. More advocates and allies are needed to continue to push issues on behalf of smaller venues at the City Hall level.

Lutz Leichsenring, one of the curious minds behind the report, points towards the competition in the music sphere around the world today and asks which cities, "are the ones attracting the brains....and the creative people?" Perhaps he states the obvious when he says, "You cannot buy creativity; you have to have an environment which creates the possibility for people to be creative." Creative Footprint NYC is the first step in this direction and will hopefully inspire others to follow in taking action to support the live music and nighttime economy.

\section{Endnotes}

1. 'NYC's Nightlife Economy Impact, Assets, and Opportunities," New York City Mayor's Office of Media and Entertainment, January 24, 2019, 3.

2. "Music in New York City," New York City Mayor's Office of Media and Entertainment, March 8, 2017, 18.

3. "Creative Footprint NYC" Report, September 28, 2018, 31.

4. "Creative Footprint NYC" Report, September 28, 2018, 31. 


\section{References}

Ahearn, Joe, Mehmet Dede, Tatiana De la Torre Arnaiz, Michael Fichman, Richard Foster, Ross Gardiner, Lutz Leichsenring, Mirik Milan, and Andreina Seijas J. "Creative Footprint NY: Measuring Live Music Space in New York City." September 28, 2018. Accessed June 15, 2019. https://www.creative-footprint.org/ new-york/\#content.

Baer, Drake. "Amsterdam's 'night mayor' is turning his city into a 24-hour adventure." Business Insider. February 18, 2016. Accessed June 17, 2019. https:// www.businessinsider.com/mirik-milan-amsterdam-night-mayor-2016-2.

Codrea-Rado, Anna. "What Europe's 'Night Mayors' Can Teach New York." New York Times. August 30, 2017. Accessed June 17, 2019. https://www.nytimes. com/2017/08/30/arts/new-york-night-mayor-europe. html.

Feuer, Alan. "New York City Appoints Its First Nightlife Mayor." New York Times. March 7, 2018. Accessed June 15, 2019. https://www.nytimes.com/2018/03/07/ nyregion/nyc-nightlife-mayor.html.

Lerner, Jane. "With Its 'No Dancing' Law Verging On Repeal, New York Legitimizes Its Nightlife." NPR. September 20, 2017. Accessed June 17, 2019. https://www.npr.org/sections/therecord/2017/09/20/552292586/with-its-no-dancing-lawverging-on-repeal-new-york-legitimizes-its-nightlife.

Levine, Alexandra S. "New York Today: The Nightlife Mayor's Citywide Tour." New York Times. October 1, 2018. Accessed June 15, 2019. https://www.nytimes. com/2018/10/01/nyregion/new-york-today-the-nightlife-mayors-citywide-tour.html.

New York City Mayor's Office of Media and Entertainment. "Music in New York City." March 8, 2017. Accessed June 15, 2019. https://www1.nyc.gov/assets/ mome/pdf/MOME_Music_Report_2017_DIGITAL. pdf.

New York City Mayor's Office of Media and Entertainment. "NYC's Nightlife Economy: Impact, Assets, and Opportunities." January 24, 2019. Accessed June 15, 2019. https://www1.nyc.gov/assets/mome/pdf/NYC Nightlife_Economic_Impact_Report_2019 digital.pdf. O'Sullivan, Feargus. "How to Be a Good 'Night Mayor."” CityLab. September 26, 2017. Accessed June 17, 2019. https://www.citylab.com/solutions/2017/09/america-discovers-the-night-mayor/539505.
Mehmet Dede, M.A. in Music Business (New York University), B.S. in Engineering (Istanbul Technical University), joined the Music Industry department at the Hartt School, University of Hartford as Assistant Professor in 2016. An established music presenter and tour producer in New York, Dede currently serves as Director of Programming at Drom, a 300 people-capacity music club in downtown Manhattan and is the curator of the NY Gypsy Festival. He is an alumnus of Leadership Music in Nashville and was profiled in The Wall Street Journal, Forbes and Inside Arts Magazine.

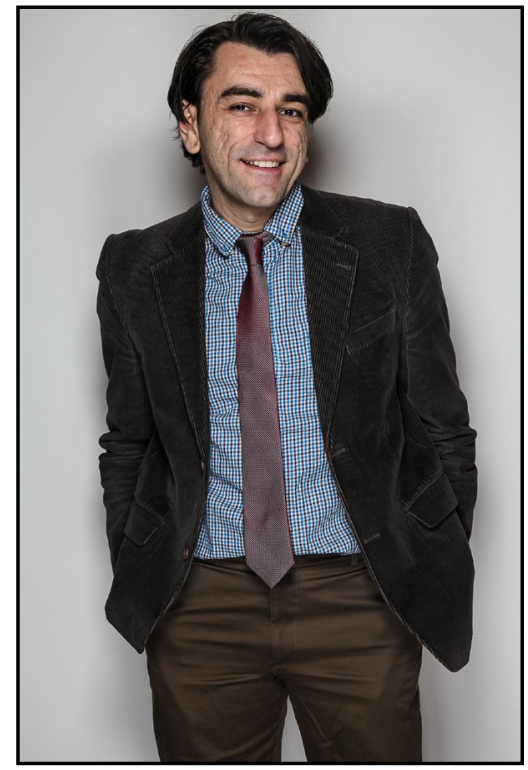




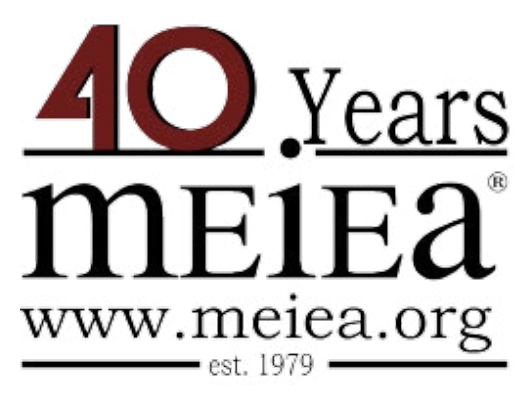

\section{PROCEEDINGS OF THE \\ 2019 INTERNATIONAL SUMMIT \\ OF THE \\ MUSIC \& ENTERTAINMENT \\ INDUSTRY EDUCATORS \\ ASSOCIATION}

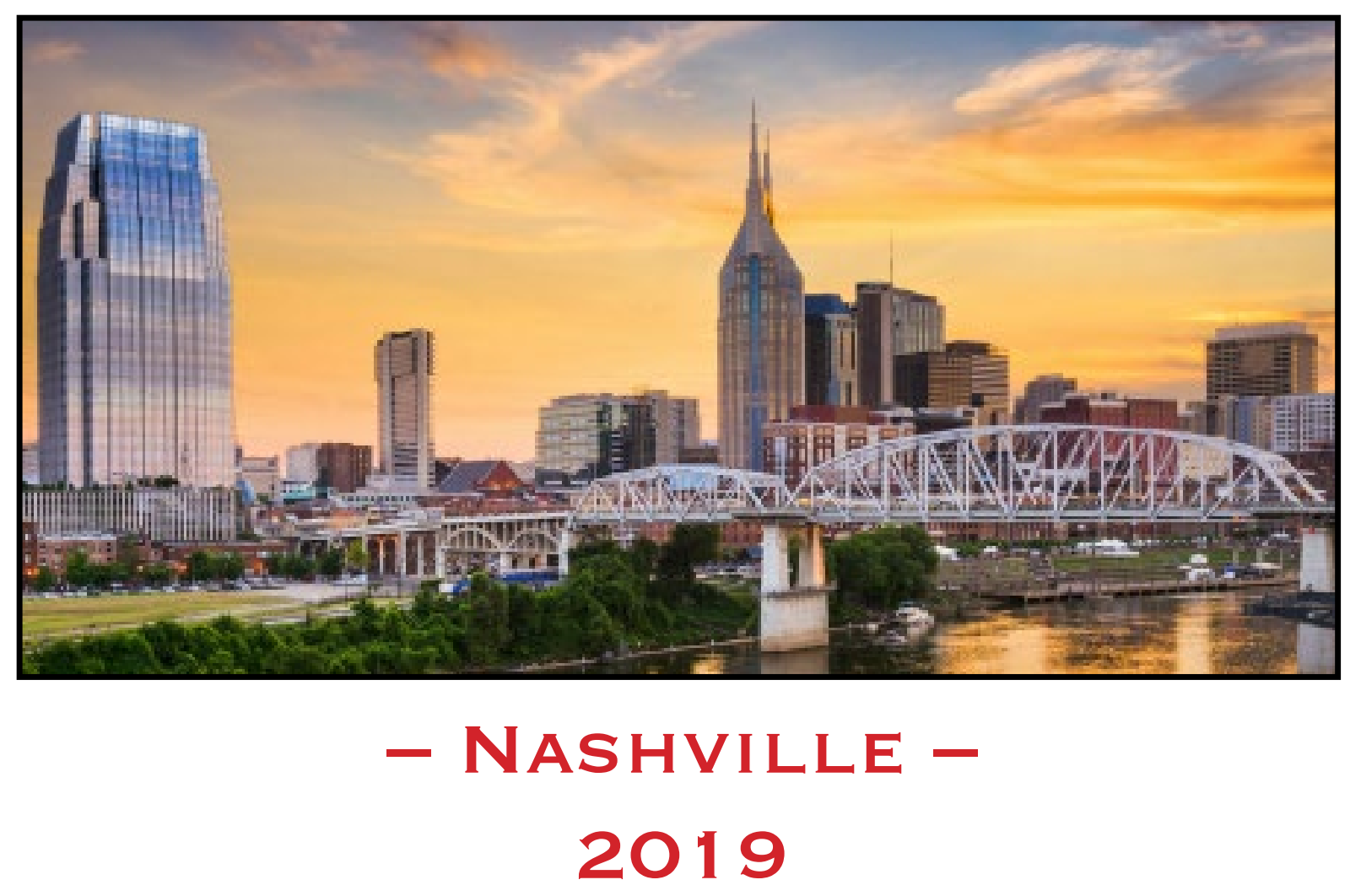

March 21 - 23, $2019 \cdot$ Belmont University - Nashville 